\title{
UM ESTUDO COM IDOSOS: ABORDAGEM DE SUAS NECESSIDADES FISIOLÓGICAS PARA O DESENVOLVIMENTO DE PRODUTOS DE MODA INCLUSIVA
}

\section{A STUDY WITH THE ELDERLY: APPROACHING THEIR PHYSIOLOGICAL NEEDS FOR THE DEVELOPMENT OF INCLUSIVE FASHION PRODUCTS}

\author{
Thiago Varnier ${ }^{1}$, Mestrando \\ Rachel Corrêa de Quadros², Me \\ (1) Universidade Federal de Santa Catarina (UFSC) \\ e-mail: thiago.varnier@posgrad.ufsc.br \\ (2) Universidade Comunitária da Região de Chapecó (UNOCHAPECÓ) \\ e-mail: rachelcq@unochapeco.edu.br
}

Idosos, moda inclusiva, ergonomia

\begin{abstract}
O aumento do envelhecimento populacional demanda estudos acerca das necessidades de melhoria na qualidade de vida dessa população. Diante disso, é importante pesquisar sobre o envelhecimento com a finalidade de conhecer as necessidades específicas dos idosos, promovendo a inclusão e possibilitando avanços significativos na relação idoso versus produtos. O estudo teve como objetivo investigar as principais alterações fisiológicas, da população idosa, na premissa de relacionar aos projetos de moda inclusiva. A metodologia proposta é um estudo quantitativo descritivo observacional. Percebe-se com os resultados obtidos que deve-se levar em conta as especificidades que caracterizam as idosas em geral e não como uma categoria única. Dessa forma os resultados da pesquisa podem futuramente serem utilizados no processo de desenvolvimento de produtos de moda inclusiva para idosos que proporcionem uma interação mais confortável e benéfica entre os idosos e suas vestimentas, relacionado os fatores termofisiológicos.
\end{abstract}

\section{Elderly, inclusive fashion, ergonomics}

The increase of the population demandsstudies on the needs of improvements in the quality of life of the population. In view of this, it is important to research about aging in order to know the specific needs of the elderly, promoting inclusion and making significant advances in the elderly versus products relationship. The objective of this research was to investigate the main physiological alterations, of the elderly population, on the premise of relating inclusive fashion projects. The proposed methodology is a descriptive quantitative observational study. It can be seen from the results obtained that the specificities characterizing the elderly in general and not as a single category must be taken into account. In this way the results of the research can be used in the process of developing inclusive fashion products for the elderly that provide a more comfortable and beneficial interaction between the elderly and their clothing, related to thermophysiological factors.

\section{Introdução}

A qualidade de vida não é um simples modismo, mas sim uma necessidade ampla de uma sociedade em constante desenvolvimento, que busca condições adequadas de vida, contribuindo para o bem físico e espiritual. Dessa forma, é importante pesquisar os variados públicos, com a finalidade de conhecer as necessidades específicas do ser
Realização:
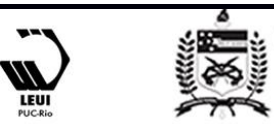


\section{$16^{\circ}$ \\ ERGODESIGN USIHC CINAHPA}

humano, promovendo a inclusão e possibilitando melhorias na qualidade de vida de todos.

Cardoso (2012) em sua obra, assinala um grande avanço quando designers reconhecem a complexidade dos sistemas, e passam a direcionar seus projetos a procura de soluções que visam progressos na sociedade, principalmente no que diz respeito ao acesso à qualidade de vida dos usuários, ou seja, que os designers saiam de seu universo autorreferente para projetarem soluções plausíveis para um mundo real. "O design é um campo essencialmente híbrido que opera a junção entre corpo e informação, entre artefato, usuário e sistema" (CARDOSO, 2012, p.237).

Pensando na área de design inclusivo, um dos grupos de usuários que refere-se a necessidades projetuais específicas são os idosos. Pode-se dizer que as pesquisas que envolvem o envelhecimento vêm ganhando mais espaço em estudos científicos, em virtude da ascensão do número de idosos no mundo (CONVERSO; LARTELLI, 2007).

O aumento constante da longevidade humana representa uma das maiores transformações e desafios dos nossos tempos. Segundo previsões da Organização Mundial da Saúde (2015) daqui há 35 anos, o mundo terá o dobro de idosos. O mesmo órgão contabiliza cerca de 900 milhões de idosos atualmente, ou cerca de $12,3 \%$ da população total. A expectativa é de que em 2050, representem $21,5 \%$, mais de um quinto do planeta (cerca de 2 bilhões).

É possível afirmar que apesar da elevação do número de idosos, esses usuários não são atendidos pela maioria dos produtos. Os fatores associados ao processo de envelhecimento e as formas corporais, podem ser considerados como elementos de influência para projetos e pesquisas no desenvolvimento de uma moda diretamente relacionada a esse público.

\footnotetext{
${ }^{1}$ Informação contida no Relatório Mundial de Envelhecimento e Saúde. Disponível em:< http://sbgg.org.br/wp-content/uploads/2015/10/OMSENVELHECIMENTO-2015-port.pdf > Acesso em: 18/Ago/2016.
}

$16^{\circ}$ Ergodesign - Congresso Internacional de Ergonomia e Usabilidade de Interfaces Humano Tecnológica: Produto, Informações Ambientes Construídos e Transporte

$16^{\circ}$ USIHC - Congresso Internacional de Ergonomia e Usabilidade de Interfaces Humano Computador

CINAHPA | 2017 - Congresso Internacional de Ambientes Hipermídia para Aprendizagem.
Para Monge (2012), o design inclusivo é importante na perspectiva da "mudança do envelhecimento" e do "design para o nosso futuro", justifica-se dizendo: os idosos não querem ser considerados "deficientes". Gostam de manter o conforto, a acessibilidade e a independência a que estão habituados. Consequentemente, nem aceitam produtos quotidianos difíceis de usar nem produtos de "assistência" estigmatizantes como um sinal de envelhecimento. Isto significa que a atitude dos que projetam, produzem e fornecem estes produtos terá de mudar radicalmente (MONGE, 2012, p.120).

A partir dessas constatações, pode-se dizer que o design inclusivo é um campo de pesquisa que necessita ser muito mais abordado e explorado por designers, com a finalidade de encontrar soluções criativas para novos projetos que combinem inclusão, acessibilidade e funcionalidade.

Neste artigo o propósito é realizar um recorte do Trabalho de Conclusão de Curso, do curso de Design- ênfase em Moda, da Universidade Comunitária da Região de ChapecóUNOCHAPECÓ. O objetivo dessa pesquisa citada, foi compreender a interação de idosos com suas vestimentas, considerando a morfologia e fisiologia do corpo humano, precisamente direcionada aos aspectos fisiológicos dos sujeitos, relacionando sobretudo, a sensibilidade térmica, para entender o comportamento das roupas em contato com o corpo e identificar as reais necessidades dos usuários.

No que tange, este artigo tem por objetivo aproximar os aspectos fisiológicos das idosas aos projetos de moda inclusiva com a finalidade de projetar produtos satisfatórios que ofereçam funcionalidade, usabilidade e conforto. Nesse contexto de vislumbrar um futuro cada vez mais preocupado com os seres humanos, se faz necessário ressalvar que o design no âmbito da pesquisa, justifica-se de alguma forma, em querer melhorar a interação entre usuários e produtos com foco na satisfação e bem estar da humanidade.

Dessa forma, é importante estudar os variados públicos com a finalidade de conhecer as 


\section{$16^{\circ}$ \\ ERGODESIGN USIHC CINAHPA}

$16^{\circ}$ Ergodesign - Congresso Internacional de Ergonomia e Usabilidade de Interfaces Humano Tecnológica: Produto, Informações Ambientes Construídos e Transporte

$16^{\circ}$ USIHC - Congresso Internacional de Ergonomia e Usabilidade de Interfaces Humano Computador

CINAHPA | 2017 - Congresso Internacional de Ambientes Hipermídia para Aprendizagem. necessidades especificas nos requisitos de projetos, promovendo inclusão e qualidade de vida (GRUBER, 2014).

Richards (1981), afirma que os idosos podem ter necessidades específicas e identificáveis em relação com as roupas, que são resultantes das mudanças fisiológicas as quais ocorrem com o passar do tempo. Argumenta-se, portanto que é relevante conhecer o aspecto biológico e funcional do idoso, para o desenvolvimento de produtos, levando-se em conta as necessidades fisiológicas desse público específico, possibilitando melhoria na qualidade de vida e consequentemente tratar aspectos relativos ao desconforto das peças de vestuários percebidas pelo público idoso, garantindo benefícios significativos. Dessa forma é valido ampliar e entender essa rede de complexidade sobre o fenômeno do envelhecimento.

\section{Referencial Teórico}

\subsection{Envelhecimento Humano}

Segundo Spirduso (2005, p.6), envelhecimento refere-se a "um processo ou conjunto de processos que ocorrem em organismos vivos e que com o passar do tempo levam a uma perda da adaptabilidade, deficiência funcional, e, finalmente, à morte". Essa autora define o envelhecimento através dos processos fisiológicos em crescimento e desenvolvimento.

O processo de envelhecimento é inerente ao ser humano, o grau em que ocorrerá e seus efeitos variam em virtude dos fatores genéticos, da qualidade de vida e meio social. Percebe-se que todo o ser humano em idade avançada pode apresentar dificuldades e características peculiares, sendo assim se faz necessário evidenciar um projeto de vestuário para idosos ponderando os inúmeros aspectos do envelhecimento agregando aos produtos características funcionais que melhorem a interface usuário versus roupas versus tarefas (MENEGUCCI; SANTOS FILHO, 2010).

A partir dos estudos baseados em Morelli e Rebelatto (2007), constatou-se que uma das alterações mais evidentes anátomo-fisiológicas característica do processo de envelhecimento é perda de massa muscular, que ocorre principalmente pela diminuição no peso muscular, consequentemente, "o idoso terá menor qualidade em sua contração muscular, menor força, menor coordenação dos movimentos e, provavelmente, maior probabilidade de sofrer acidentes (por exemplo, quedas)" (MORELLI; REBELATTO, 2007, p. 72).

Para Spirduso (2005), a pele é a grande reveladora do envelhecimento, pois torna-se fina, pálida, menos elástica e moldável, menos eficiente na termorregulação, com menor capacidade de produzir suor, e de exibir resposta inflamatória, sendo grande parte dessas mudanças causadas pela diminuição da circulação para a derme.

Cabe então aos designers pensar de forma inclusiva nas reais necessidades desse nicho, buscando soluções para requisitos de projeto que possibilite desenvolver um produto com qualidade, segurança e competência, onde o desafio é encontrar uma solução que promova a comunicação dos resultados. Em consequência disso, se faz importante associar a abordagem do design inclusivo como uma maneira de possibilitar maior acessibilidade e independência na vida dos usuários, onde os designers devem estar cientes das necessidades únicas do seu público, projetando assim, de forma inclusiva, atendendo exclusivamente o problema em questão.

Dessa maneira, pode-se observar um contexto de oportunidade de mercado, através de uma lacuna de um segmento específico, chamada de moda inclusiva, destacando a importância do ser humano no processo de design, visando o conhecimento do corpo humano na sua totalidade, proporcionando melhorias na qualidade de vida.

\subsection{Moda Inclusiva}

A abordagem inclusiva, na moda, é muito recente. Conforme pode ser observado na história da evolução da indumentária o corpo sempre se adaptou às estruturas das vestimentas. Segundo Braga (2007), a partir do final do século XIX,
Realização:

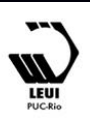




\section{$16^{\circ}$ \\ ERGODESIGN USIHC CINAHPA}

surgem movimentos por uma roupa que proporcione conforto e se adapte as formas do corpo.

De acordo com Carli e Manfredini (2010), moda inclusiva é uma proposta nova que propõe incluir tipos de corpo que a indústria hoje não contempla. A moda deve olhar para aspectos como a ergonomia, a mobilidade e a funcionalidade das peças. Assim, moda inclusiva vai além e pretende incluir pessoas com deficiência e necessidades especificas, com a finalidade de facilitar o cotidiano dessas pessoas apresentando soluções e inovações nas modelagens das peças e em seu acabamento, estendendo o conforto para todas as pessoas com ou sem deficiência.

A este respeito, Auler (2012), assinala que pensar em moda inclusiva pode ser estimulante para os designers, pois estes podem desenvolver projetos de produtos para vestuário e propor soluções inovadoras, de forma a tonar a moda muito mais democrática. "Dentro do campo do design, pensar em um tipo de moda completamente diferente do que foi pensado até hoje, significa inovar, romper barreiras e ganhar valores de vanguarda" (AULER, 2012, p. 17).

A partir dessa concepção, percebe-se que tanto a moda inclusiva quanto o design inclusivo, são campos de pesquisa que necessitam ser muito mais pesquisados e explorados por designers, com a finalidade de encontrar soluções criativas para novos projetos que combinem inclusão, acessibilidade e sustentabilidade social associando sempre os fatores humanos - a ergonomia.

\subsection{Ergonomia}

O conceito de ergonomia pode ser compreendido a partir do pensamento de Iida (2005) como sendo um estudo do relacionamento entre o homem e seu trabalho, equipamento e ambiente e,

particularmente, a aplicação dos conhecimentos de anatomia, fisiologia e psicologia na solução dos problemas surgidos desse relacionamento. $16^{\circ}$ Ergodesign - Congresso Internacional de Ergonomia e Usabilidade de Interfaces Humano Tecnológica: Produto, Informações Ambientes Construídos e Transporte

$16^{\circ}$ USIHC - Congresso Internacional de Ergonomia e Usabilidade de Interfaces Humano Computador

CINAHPA | 2017 - Congresso Internacional de Ambientes Hipermídia para Aprendizagem.

Segundo a Associação Brasileira de Ergonomia ${ }^{2}$ (ABERGO, 2015) a ergonomia (ou Fatores Humanos), é uma disciplina científica relacionada ao entendimento das interações entre o seres humanos e outros elementos ou sistemas, e à aplicação de teorias, princípios, dados e métodos a projetos afim de otimizar o bem-estar humano e o desempenho global do sistema.

Isto posto, é possível deduzir que a ergonomia é requisito obrigatório na concepção de um produto de moda, tornando um produto seguro, prático, confortável e de fácil manejo.

De acordo com Ferreira e Martins (2014), as qualidades de um produto dentro das perspectivas da ergonomia, estão relacionadas com vários fatores que possuem por objetivo satisfazer as necessidades humanas. $\mathrm{O}$ primeiro deles é a qualidade técnica, que caracteriza-se pelo funcionamento e eficiência do produto, o segundo é a qualidade ergonômica que permite adequação entre usuário e produto, facilitando movimentação, conforto, segurança e a usabilidade pretendida. E também o fator estético, que proporciona prazer ao consumidor e tornam-se desejáveis aos seus olhos.

A partir disso, a adequação do vestuário ao corpo humano tem como objetivo proporcionar o melhor aproveitamento da roupa sem lhe causar danos. Vem daí a necessidade de um estudo aprofundado para cada sujeito estabelecendo as propriedades ergonômicas preventivas, do elemento humano, com a intenção de atingir assim a funcionalidade, usabilidade e conforto das vestimentas.

\subsection{Bioergonomia}

Lacombe (2012) fundamenta que a definição adotada pela Associação Internacional de Ergonomia (IEA), em 2000, coloca a Ergonomia como uma disciplina cientifica relacionada ao entendimento das interações entre seres humanos e outros elementos do sistema. É a profissão que

${ }^{2}$ http://www.abergo.org.br/internas.php?pg=o_que_e_er gonomia> Acesso em: 26/ago/2016. 


\section{$16^{\circ}$ \\ ERGODESIGN USIHC CINAHPA}

aplica teoria, princípios, dados e métodos para projetar a otimização do bem-estar humano e de seu desempenho geral, sendo conhecida como "Ergonomia de Fatores Humanos", nos Estados Unidos. A este respeito Lacombe assinala que essa é a definição que mais se assemelha a que chamase BIOERGONOMIA (Ergonomia do Elemento Humano), conceito este presente apenas nas pesquisas de Lacombe (2012).

A partir dos estudos baseados em Lacombe, constatou-se que a bioergonomia é o conhecimento do corpo humano na sua totalidade e a utilização plena de seus recursos para tratar, curar e/ou prevenir, proporcionando uma melhor qualidade de vida. A proposta é investir no ser humano, compreendendo o funcionamento adequado do corpo. Em face disso, Lacombe (2012, p. 51) constata que "BIOERGONOMIA é o acompanhamento e o cuidado com o elemento humano, buscando seu melhor rendimento pessoal, profissional, físico, mental e melhor qualidade de vida dentro do contexto do mundo laboral".

A ergonomia dos fatores humanos prevê a adequação do mobiliário aos indivíduos e não ao trabalho educativo corporal dos trabalhadores, adaptando-os ao mobiliário e a tarefa. O modelo chamado de Bioergonomia tem por objetivos segundo Lacombe (2012, p. 40), orientar e prevenir para evitar o aparecimento ou recidivas de lesões musculoesqueléticas, tratar doenças existentes, aumentar a flexibilidade, a força, a coordenação e a resistência, diminuir o estresse, tensão ansiedade, depressão, melhorar a qualidade do sono, melhorar o bem-estar geral, diminuir acidentes de trabalho e aumentar a produtividade além de reduzir o afastamento devido a doenças ocupacionais.

Estudando Grave (2004), percebe-se que a roupa se torna compatível com o usuário, facilitando os movimentos de membros, concedendo a sensação de conforto, funcionalidade e qualidade de vida, quando ocorre uma integração de uma modelagem específica e detalhada, costuras, fios, tecidos, respeitando os movimentos de cada parte do corpo. Para a mesma autora, vestir-se é um ato preventivo. Os tecidos, aviamentos, acessórios e a tecnologia têxtil que são agregadas à vestimenta devem atender as necessidades anatômicas, fisiológicas e psicológicas assegurando a saúde do usuário.

A bioergonomia está associada a ginastica holística (GH) - Método Ehrenfried, na qual "holística", deriva do grego Holos [inteiro, total], dessa forma é um termo que refere-se a totalidade e interdependência. Dessa maneira, a GH, permite ao indivíduo descobrir suas possibilidades por meio da percepção, sem impor ritmos que não lhe são próprios. Assim a palavra holística se encaixa perfeitamente com esse significado, principalmente, à medida que observamos que $\mathrm{o}$ corpo não é segmentado, mas um todo que interage a cada movimento. Os movimentos desse método são realizados por comando de voz que dita experiências corporais novas e não habituais, estimulando áreas diferentes do cérebro. São movimentos amplos que proporcionam benefícios às cadeias musculares, equilibram a respiração, estimulam a coordenação motora, fazendo que obtenha-se um resultado duradouro, sem sobrecarga muscular ou fadiga, modificando então de forma definitiva as estruturas do corpo (LACOMBE, 2012).

Cada ser humano tem uma estrutura anatômica, fisiológica e biomecânica diferenciada, que o caracterizam como um indivíduo. Portanto, nada mais correto do que ele próprio mover-se, exercitar-se dentro de seus limites, e tomar consciência do seu físico em seu nível e grau possíveis. É desta maneira que o método consegue transmitir os conhecimentos necessários a cada um e dar capacidade de continuidade sem depender exclusivamente da presença do terapeuta (LACOMBE, 2012, p. 58).

Estudando Lacombe (2012), percebeu-se que pode haver uma lacuna entre a bioergonomia e a moda inclusiva para idosos, haja visto que esses sujeitos necessitam de um produto que traga funcionalidade, usabilidade e conforto, mas que precisamente preencha as necessidades fisiológicas do corpo e que possibilite maior independência do indivíduo de uma maneira global, através de um processo de autoanálise , no qual, o idoso precisa se envolver com o seu próprio corpo criando
Realização:

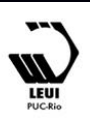




\section{$16^{\circ}$ \\ ERGODESIGN USIHC CINAHPA}

condições e respeitando seus limites.

\section{Metodologia}

A proposta metodológica em questão, é uma pesquisa aplicada com uma abordagem descritiva por meio da pesquisa quantitativa. Realizou-se pesquisa bibliográfica e estudo de caso na Clínica Escola de Fisioterapia da Universidade Comunitária da Região de Chapecó UNOCHAPECÓ $^{3}$, a qual subsigo a amostra de pesquisa, 12 (doze) idosas que realizavam tratamento fisioterapêutico. $\mathrm{O}$ fator determinante na delimitação do grupo de amostra da pesquisa, foram as questões fisiológicas que ocorrem no processo de envelhecimento. Esta pesquisa foi submetida e aprovada pelo Comitê de Ética e Pesquisa em Seres Humanos da Universidade Comunitária da Região de Chapecó

(UNOCHAPECÓ) em 27 de abril de 2016 sobre o parecer de $\mathrm{n}^{\circ}$ 1.527.743.

A avaliação fisiológica se deu por meio do protocolo de avaliação da Clínica Escola, adaptado, com a finalidade de identificar as mudanças fisiológicas decorrentes do envelhecimento. Iniciou-se pela história pregressa e medicação. Posteriormente avaliou-se os sinais vitais da sujeita para uma análise e compreensão do seu estado geral. Realizou-se exame físico avaliando a inspeção, aparência da pele e palpação das extremidades (mãos e pés). E por fim, foi realizado a avaliação sensorial da pele, que teve por objetivo medir a sensibilidade. Iniciou-se pela avaliação de sensibilidade tátil, identificando a sensibilidade da pele, seguindo o mapa dos dermátomos (figura 1). Para este procedimento

\footnotetext{
${ }^{3}$ Iniciou suas atividades em agosto de 2007. Os espaços físicos, contam com estruturas para atender as necessidades das mais diversas áreas atendidas pela fisioterapia, bem como cardiorrespiratória, disfunções, gerontologia, oncologia, neurologia adulta e infantil, e saúde coletiva. Para isso, a Clínica possui salas de avaliações, salas de eletrotermoterapia, cinesioterapia e mecanoterapia, além de sala de neurologia infantil e salas para atendimentos coletivos.
}

$16^{\circ}$ Ergodesign - Congresso Internacional de Ergonomia e Usabilidade de Interfaces Humano Tecnológica: Produto, Informações Ambientes Construídos e Transporte

$16^{\circ}$ USIHC - Congresso Internacional de Ergonomia e Usabilidade de Interfaces Humano Computador

CINAHPA | 2017 - Congresso Internacional de Ambientes Hipermídia para Aprendizagem.

utilizou-se o estesiômetro ${ }^{4}$. A avaliação foi realizada com a idosa vendada, onde foi avaliado mãos na face palmar os dermátomos C6, C7 e C8, posteriormente a face do dorso, os dermátomos C6 e C8.

O teste iniciou com o monofilamento mais leve (verde), e a sujeita respondia "sim" quando sentisse o toque do filamento, neste caso a sensibilidade é perceptível/ preservada. $\mathrm{Na}$ ausência de resposta, procedesse para o próximo filamento mais espesso (azul) e assim progressivamente (violeta), (vermelho escuro), (laranja) e por fim (vermelho magenta) nessa ordem até obter-se uma resposta. Não obtendo nenhuma resposta sugere-se perda da sensibilidade à pressão profunda. $\mathrm{O}$ mesmo procedimento foi realizado nos pés, avaliando no dorso os dermátomos S1, e na face plantar os dermátomos L5 e S1.

Figura 1: Mapa dos dermátomos

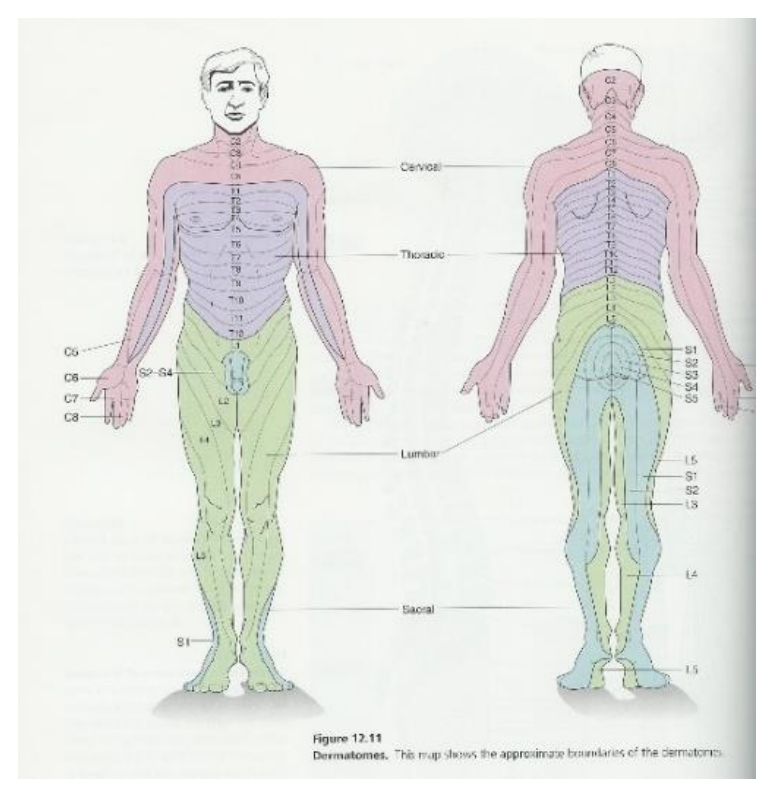

Fonte: NETTER, Frank H. Atlas de anatomia humana. 3. ed. Porto Alegre: Artmed, 2004.

\footnotetext{
${ }^{4}$ Kit para testes de sensibilidade. Filamentos de nylon de diferentes cores que avaliam a percepção da sensibilidade da pele.
}

Realização:

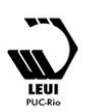




\section{$16^{\circ}$ \\ ERGODESIGN USIHC CINAHPA}

Realizou-se também um teste de sensibilidade tátil tanto para mãos quanto para pés com alguns instrumentos: esponja macia e áspera; algodão e rolo crespo. Para esse teste, a idosa também era vendada em seus olhos. Os instrumentos foram passados sobre as extremidades (mãos e pés) e a sujeita relatava a sensação de sensibilidade, ou mesmo a identificação do objeto. A finalidade era compreender se a sensibilidade era presente com objetos de diferentes texturas.

Posteriormente, foi realizado o teste de avaliação de sensibilidade dolorosa, cuja a finalidade era a percepção da dor relatada pela idosa. Para esse teste utilizou-se o monofilamento magenta, passando nas extremidades (mãos e pés) seguindo o mapa dos dermátomos, C6, C7 e C8 para mãos e L5 e S1 para os pés.

Enfim para finalizar a avaliação sensorial, realizou-se o teste térmico. Para o teste de calor utilizou-se de uma bolsa térmica de água quente $\left( \pm 36^{\circ} \mathrm{C}\right)$ e para o teste de frio uma bolsa térmica de gelo $\left( \pm 0^{\circ} \mathrm{C}\right)$ com a finalidade de identificar as regiões de alterações, variações e percepção de temperatura. A idosa manteve-se vendada, e o teste também foi realizado nas extremidades (mãos e pés). As bolsas eram alternadas entre a quente e fria, nas regiões da face dorso e face palmar das mãos e na face dorso e face plantar dos pés. As percepções de temperaturas eram registradas na avaliação fisiológica.

\section{Resultados}

Após a coleta de dados, todos foram tabulados e decodificados em programa Microsoft Excel versão 2010. Para análise dos dados utilizouse Microsoft Excel versão 2010. As variáveis numéricas foram representadas em valores relativos e absolutos por média, desvio padrão e percentil. Os dados foram apresentados na forma de tabelas. Já para as variáveis qualitativas os dados foram apresentados por agregação de categorias, em forma de tabelas e descrição. Todos os aspectos éticos foram assegurados pelos autores com o pleno consentimento dos participantes e sigilo de identidade. $16^{\circ}$ Ergodesign - Congresso Internacional de Ergonomia e Usabilidade de Interfaces Humano Tecnológica: Produto, Informações Ambientes Construídos e Transporte

$16^{\circ}$ USIHC - Congresso Internacional de Ergonomia e Usabilidade de Interfaces Humano Computador

CINAHPA | 2017 - Congresso Internacional de Ambientes Hipermídia para Aprendizagem.
Diante da história pregressa (cirurgia, antecedentes patológicos), a amostra revelou que apenas três idosas não tinham realizado nenhum procedimento cirúrgico, enquanto nove haviam passado por cirurgias. As com predominância foram as cesárias, apendicite, hérnia, vesícula, bexiga, além de cirurgias da coluna, joelho e ombro.

De acordo, com os sinais vitais, representados na tabela 1, percebe-se que a média da Frequência Cardíaca (FC) encontrou-se em 76,75 ( $\pm 2,8)$ bpm. No que se refere a Frequência Respiratória (FR) encontrou-se em 15,75 $( \pm 0,82)$ irpm, foi observado que ambas encontraram-se dentro da normalidade.

Tabela 1- Sinais Vitais

\begin{tabular}{ll}
\hline & Sinais Vitais $(\mathrm{n}=12)$ \\
\hline FC $(\mathrm{bpm})$ & $76,75( \pm 2,8)$ \\
FR (irpm) & $15,75( \pm 0,82)$ \\
PAS $(\mathrm{mmHg})$ & $125,83( \pm 8,62)$ \\
PAD $(\mathrm{mmHg})$ & $83,33( \pm 11,05)$ \\
Massa $(\mathrm{Kg})$ & $74( \pm 4,78)$ \\
Estatura $(\mathrm{cm})$ & $1,57( \pm 0,05)$ \\
IMC $\left(\mathrm{kg} / \mathrm{m}^{2}\right)$ & $30,03( \pm 2,67)$ \\
\hline
\end{tabular}

Fonte: Dados da pesquisa, 2016.

De acordo com as variáveis representadas pela tabela 1 foi possível visualizar que tanto a Pressão Arterial Sistólica (PAS) representada por uma média de $125,83 \mathrm{mmHg}$ quanto a Pressão Arterial Diastólica (PAD) representada por uma média de $83,33 \mathrm{mmHg}$ se encontram dentro dos parâmetros de normalidade para a população idosa.

Para identificar o Índice de Massa Corporal (IMC), a massa corporal foi dividida pela estatura ao quadrado. Observou-se que a média da variável IMC não encontra-se dentro dos valores de normalidade, sendo representada por uma média de $30,03 \mathrm{~kg} / \mathrm{m}^{2}$. Essas variáveis alteradas foi representada por $100 \%$ (12) da amostra. No que se refere ao IMC segundo, Bray (1992) os parâmetros de normalidade de idosos indiferente do gênero é representado entre 19 e $25 \mathrm{~kg} / \mathrm{m}^{2}$.

Em relação ao exame físico, avaliando a inspeção, aparência da pele, palpação e relato de sintomas todas as idosas apresentaram pele íntegra e normal,
Realização:

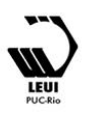




\section{$16^{\circ}$ \\ ERGODESIGN USIHC CINAHPA}

porém notou-se em seis idosas característica de pele bem fina, em duas idosas mãos e pés ressecados, justifica-se estas alterações decorrente do envelhecimento. Nenhuma das idosas sentia dor e somente uma relatava parestesia nos pés (amortecidos).

De acordo com a avaliação sensorial, foram abordados as sensibilidades tátil, dolorosa e térmica. No teste tátil identificou-se que a maioria das idosas possuem perda da sensibilidade tátil, ou seja, dificuldades quanto a discriminação de forma e temperatura além da perda da sensação protetora, sendo suscetível a lesões.

Quando realizado o teste de sensibilidade tátil com os materiais: esponja macia e áspera, algodão e rolo crespo, as idosas relataram as percepções de acordo com a tabela 2 .

Tabela 2- Teste de Sensibilidade Tátil com Diferentes Materiais

\begin{tabular}{|c|c|c|c|c|c|c|c|c|}
\hline \multicolumn{9}{|c|}{ Material $(n=12)$} \\
\hline & \multicolumn{2}{|c|}{$\begin{array}{l}\text { Esponja } \\
\text { Macia } \\
\text { Mãos* } \\
\text { Pés* }\end{array}$} & \multicolumn{2}{|c|}{$\begin{array}{l}\text { Esponja } \\
\text { Áspera } \\
\text { Mãos* } \\
\text { Pés* }\end{array}$} & \multicolumn{2}{|c|}{$\begin{array}{l}\text { Algodão } \\
\text { Mãos* } \\
\text { Pés* }\end{array}$} & \multicolumn{2}{|c|}{$\begin{array}{l}\text { Rolo } \\
\text { crespo } \\
\text { Mãos* } \\
\text { Pés* }\end{array}$} \\
\hline Perceptível & 12 & 11 & 8 & 7 & 12 & 12 & 11 & 10 \\
\hline Macia $^{\#}$ & - & - & 4 & 5 & - & - & - & - \\
\hline Rígida" & - & 1 & - & - & - & - & - & - \\
\hline Lisa $^{\#}$ & - & - & - & - & - & - & 1 & 2 \\
\hline
\end{tabular}

Diante disso, pode-se perceber que todas as idosas tiveram percepção dos materiais (sentiram o toque dos materiais), esponja macia, esponja áspera, algodão e rolo crespo, tanto para mãos quanto para pés. Os materiais que tiveram maior percepção foram: em primeiro lugar o algodão, em segundo lugar foi a esponja macia, em terceiro lugar rolo crespo e em quarto lugar a esponja áspera, todos ambos para mãos e pés.

Em relação ao teste de sensibilidade dolorosa, tanto para mãos sendo face palmar dermátomos (C6, C7 e C8) e dorso dermátomos (C6 e C8), quanto para os pés, face plantar dermátomos (L5 e S1) e dorso dermátomos (S1), houve presença da sensibilidade dolorosa, ou seja, não teve nenhuma alteração. $16^{\circ}$ Ergodesign - Congresso Internacional de Ergonomia e Usabilidade de Interfaces Humano Tecnológica: Produto, Informações Ambientes Construídos e Transporte

$16^{\circ}$ USIHC - Congresso Internacional de Ergonomia e Usabilidade de Interfaces Humano Computador

CINAHPA | 2017 - Congresso Internacional de Ambientes Hipermídia para Aprendizagem.

De acordo com os dados analisados no teste térmico pode-se perceber que na sensibilidade térmica para mãos frio $66,66 \%$ (oito) tem uma percepção normal enquanto 33,33\% (quatro) tem perda de sensibilidade moderada. Para os pés $25 \%$ (três) tem uma percepção normal, 66,66\% (oito) tem perda de sensibilidade modera e $8,33 \%$ (uma) apresentou alteração de sensibilidade para o frio, ou seja, relatou sentir o frio quente. Enquanto que para a sensibilidade térmica para mãos calor $58,33 \%$ (sete) tem uma percepção normal, já 41,66\% (cinco) tem perda de sensibilidade moderada. Para os pés $41,66 \%$ (cinco) tem um percepção normal e 58,33\% (sete) tem perda de sensibilidade moderada.

Contudo, na avaliação fisiológica, identificou-se que a maioria das idosas possuem perda da sensibilidade tátil, ou seja, dificuldades quanto a discriminação de forma e temperatura além da perda da sensação protetora, sendo suscetível a lesões; enquanto o teste térmico revelou que a temperatura corporal é um fator determinante de pesquisa bioergonômica na projeção de um produto para idoso, visto que os dados revelaram as necessidades específicas das idosas quanto as variações de temperatura nas regiões do corpo, como pode-se perceber na figura 2 os dermátomos coloridos, identificando as regiões com necessidade de conforto térmico de acordo com as avaliações fisiológicas realizadas nos dermátomos C6, C7, C8, S1 e L5.

Figura 2: Variações de temperatura por regiões nos dermátomos

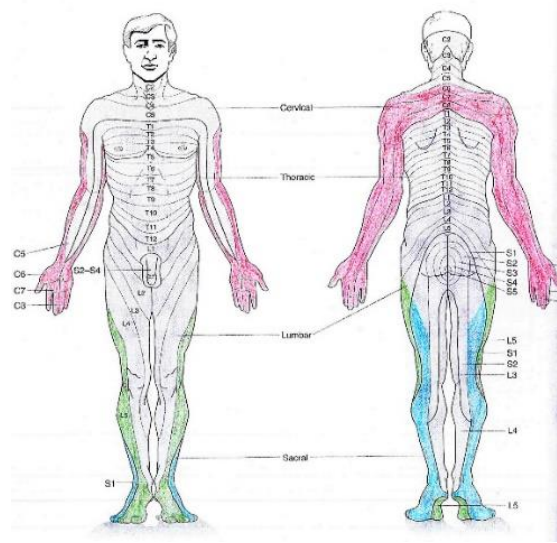

Fonte: Dados da pesquisa, 2016. 


\section{$16^{\circ}$ \\ ERGODESIGN USIHC CINAHPA}

De acordo com a figura 2 , no que condiz que os dermátomos C6, C7 e C8 (vermelhos) da mão também correspondem com a vista lateral e posterior dos braços, além da região dorsal da coluna e os dermátomos S1 (azul) e L5 (verde) dos pés também correspondem com a vista lateral e posterior das pernas, verifica-se a necessidade de realizar um artigo têxtil aliando a tecnologia têxtil, com o intuito de trabalhar esses pontos estratégicos associando o conforto térmico ao produto de moda garantindo o bem estar do indivíduo e contribuindo com a relação entre moda e corpo.

Dessa maneira, foi realizado o desenvolvimento de projeto na área de design com o intuito de desenvolver um artigo têxtil (agasalho atemporal) nas premissas da funcionalidade, usabilidade $\mathrm{e}$ conforto. No que tange, utilizou-se como matéria prima a malha de helanca ${ }^{5}$ com um enchimento da COLTEC NEVES e CIA, empresa de Portugal, o qual possui em sua composição microcápsulas de $\mathrm{PCM}^{6}$ com função de termorregulação, aplicado na vestimenta com trabalho de matelassê $\hat{e}^{7}$, nas regiões específicas identificadas na pesquisa, conforme pode-se observar na figura 3 , de modo que este agasalho venha contribuir na relação idoso e necessidades fisiológicas.

\footnotetext{
${ }^{5}$ Utilizada pela facilidade de vestir (possui elasticidade) propiciando conforto, um toque macio e suave que remete a sensação de aconchego e delicadeza e também pela resistência e durabilidade.
}

\footnotetext{
${ }^{6}$ Material com função de mudança de fase. Atua como uma esponja, mantendo o calor do corpo em aproximadamente $28^{\circ} \mathrm{C}$.

${ }^{7}$ Trabalho realizado com pespontos, em um tecido dobrado ou acolchoado, formando um desenho em auto relevo. Disponível em:

https://www.google.com.br/webhp?sourceid=chromeinstant\&ion $=1 \&$ espv $=2 \&$ ie $=U T F-$

$8 \# q=0+q u e+\% \mathrm{C} 3 \% \mathrm{~A} 9+$ matelass $\% \mathrm{C} 3 \% \mathrm{AA}>$ Acesso em: $20 /$ out/2016.
}

$16^{\circ}$ Ergodesign - Congresso Internacional de Ergonomia e Usabilidade de Interfaces Humano Tecnológica: Produto, Informações Ambientes Construídos e Transporte

$16^{\circ}$ USIHC - Congresso Internacional de Ergonomia e Usabilidade de Interfaces Humano Computador

CINAHPA | 2017 - Congresso Internacional de Ambientes Hipermídia para Aprendizagem.
Figura 3: Agasalho Atemporal

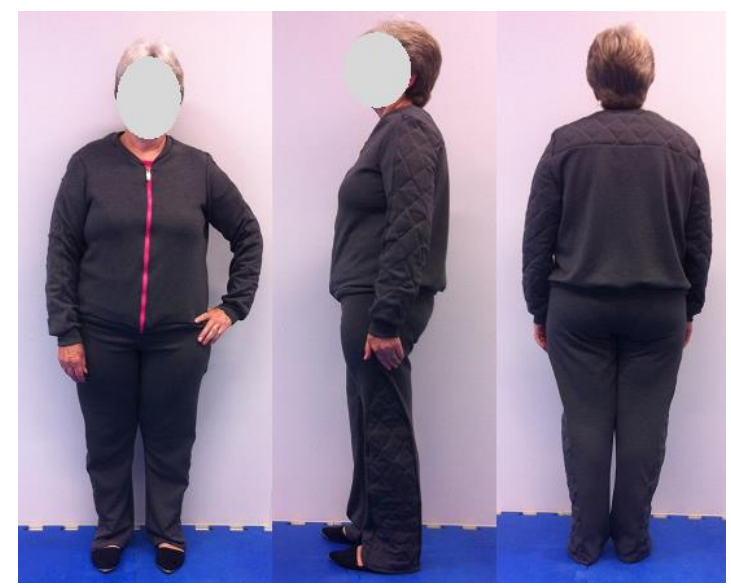

Fonte: Pesquisador, 2016.

Para os aviamentos, utilizou-se de possibilidades que favorecessem o vestir e principalmente a comodidade da idosa. Para tanto, na calça foi utilizado a malha de helanca sob um cós alto e duplo, favorecendo o ajuste na cintura. Para o fechamento do casaco, foi utilizado um zíper maior (grosso) com cursor anatômico e grande que favoreçesse o vestir. A escolha desse aviamento para o fechamento ocorreu pelo fato do ziper propiciar melhor vedamento que o botão contribuindo com o conforto térmico necessário.

Diante do exposto, pode-se concluir que distribuindo a fibra da COLTEC com funcionalidade de termorregulação em pontos estratégicos investigados neste estudo, é de suma relevância para as idosas, pois propicia uma vestimenta com conforto, usabilidade e principalmente funcionalidade, a qual atende as necessidades fisiológicas referente as questões de termorregulação corporal. Assim pode-se perceber a importância de investigar as necessidades fisiológicas das idosas na projeção de uma vestimenta que atenda às suas limitações.

\section{Considerações Finais}

Como observou-se na revisão de literatura percebese que a ergonomia aplica teorias, princípios, dados, métodos e métrica/protocolos que buscam preservar a vida humana, solucionando problemas relacionados a saúde, segurança, conforto e eficiência. Além dos fatores ergonômicos serem 


\section{$16^{\circ}$ \\ ERGODESIGN USIHC CINAHPA}

requisitos obrigatórios no desenvolvimento de projeto de moda para idosas, deve-se somar a eles os fatores fisiológicos no sentido de ampliar e entender essa rede de complexidade sobre o fenômeno do envelhecimento.

Com o estudo, pode-se compreender que os fatores fisiológicos são de grande relevância para projetos de moda inclusiva, permitindo assim aos designers desenvolverem produtos que ofereçam benefícios na vida do ser humano. Para tanto foi necessário se aprimorar de conhecimentos de métricas avaliativas fisiológicas de pesquisa com idosos, de modo a entender o funcionamento do corpo bem como compreender a necessidade de testes fisiológicos reconhecendo as necessidades especificas relacionadas com o fator termofisiológico, incluindo a sensibilidade tanto tátil quanto dolorosa.

O instrumento utilizado (estesiômetro), associado com técnicas padronizadas de coleta de dados, permitiu esse conhecimento e através do mapa dos dermátomos foi possível identificar pontos específicos para a realização de técnicas de design que possam solucionar esses desconfortos em relação a temperatura.

Ao investigar as principais mudanças fisiológicas dos idosos, a fundamentação teórica contribuiu significativamente pois na pesquisa de campo observou-se essas limitações de sensibilidade tátil e térmica, comprovando o arcabouço teórico, onde é possível analisar que, deve-se levar em conta as especificidades que caracterizam as idosas em geral e não como uma categoria única, afinal projetar vestuário/moda requer uma interação continua com o corpo do usuário exigindo respeito e responsabilidade, ajustando-se ergonomicamente a fim de facilitar o vestir-se, afinal o vestuário se adapta ao corpo, proporcionando-lhe conforto.

Dessa forma deve-se considerar no projeto de vestuário a satisfação de certas necessidades, onde as mudanças fisiológicas influenciam diretamente no desenvolvimento de produtos para esse público, revelando necessidades específicas principalmente relacionando os fatores termofisiológicos influenciando na relação entre o usuário e a $16^{\circ}$ Ergodesign - Congresso Internacional de Ergonomia e Usabilidade de Interfaces Humano Tecnológica: Produto, Informações Ambientes Construídos e Transporte

$16^{\circ}$ USIHC - Congresso Internacional de Ergonomia e Usabilidade de Interfaces Humano Computador

CINAHPA | 2017 - Congresso Internacional de Ambientes Hipermídia para Aprendizagem.

vestimenta. Somente assim, a moda com caráter inclusivo é "transformadora" e "tocante".

\section{Referências Bibliográficas}

ABERGO. Associação Brasileira de Ergonomia. Disponível em:

<http://www.abergo.org.br/internas.php?pg=o_que _e_ergonomia>. Acesso em: 04 set. 2015.

AULER, Daniela. O que é moda inclusiva. In: Moda inclusiva perguntas e respostas para entender o tema. São Paulo: Governo de Estado de São Paulo, 2012.

BRAGA, João. História da Moda: uma narrativa. 4 ed. rev. atual. São Paulo: editora Anhembi Morumbi, 2007.

Bray GA. Pathophysiology of obesity. Am J Clin Nutr. 1992; 55(2 Suppl):488S-94S.

CARDOSO, Rafael. Design para um mundo complexo. São Paulo: Cosac Naify, 2012.

CARLI, Ana Mery Schbe de; MANFREDINI, Mercedes Lusa (Orgs.). Moda e Sintonia. Caxias do Sul: EDUCS, 2010.

CONVERSO, Maria Estelita Rojas; LARTELLI, Isabele. Caracterização e análise do estado mental e funcional de idosos institucionalizados em instituições públicas de longa permanência. J Bras Psiquiatria, 56(4), p. 267-272, 2007. Disponível em:< http://www.scielo.br/pdf/jbpsiq/v56n4/a05v56n4.p df> Acesso em:10/Ago/2016.

FERREIRA, Veridianna Cristina Teodoro; MARTINS, Suzana Barreto. O papel da ergonomia na moda como contraponto ao fast fashion. Congresso Brasileiro de Iniciação Científica em Design e Moda. Anais... Caxias do Sul: 2014.

GRAVE, Maria de Fátima. A modelagem sob a ótica da ergonomia. São Paulo: Zennex, 2004.

GRUBER, Crislaine. O desconforto no uso do vestuário íntimo: avaliação da percepção pelo
Realização:

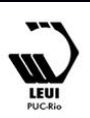




\section{$16^{\circ}$ \\ ERGODESIGN USIHC CINAHPA}

$16^{\circ}$ Ergodesign - Congresso Internacional de Ergonomia e Usabilidade de Interfaces Humano Tecnológica: Produto, Informações Ambientes Construídos e Transporte

$16^{\circ}$ USIHC - Congresso Internacional de Ergonomia e Usabilidade de Interfaces Humano Computador

CINAHPA | 2017 - Congresso Internacional de Ambientes Hipermídia para Aprendizagem.

público idoso feminino. 2014. 137 f. Dissertação (Mestrado em Design) - Universidade do Estado de Santa Catarina. Florianópolis, 2014.

IIDA, Itiro. Ergonomia: Projeto e Produção. 2 ed. São Paulo: Blucher, 2005.

LACOMBE, Patricia de Carvalho. Bioergonomia: a ergonomia do elemento humano. Curtiba: Juruá, 2012.

MENEGUCCI, Franciele; SANTOS FILHO, Abílio Garcia. Proteção e conforto: a relação entre os tecidos e o design ergonômico do vestuário para idosos. Congresso Brasileiro de Pesquisa e Desenvolvimento em Design. Anais... São Paulo, 2010.

MONGE, Nuno. Design de produtos inclusivos, satisfatórios: a abordagem holística ao design inclusivo. In: Artigos caleidoscópio revista de comunicação e cultura, n. 7, p. 117-134, 2006. Disponível em http://hdl.handle.net/10437/2679. Acesso em: 05/Ago/2016.

MORELLI, José Geraldo da Silva; REBELATTO, José Rubens. Fisioterapia Geriátrica: A prática de assistência ao idoso. 2 ed. ampl. Barueri: Maonole, 2007.

NETTER, Frank H. Atlas de anatomia humana. 3. ed. Porto Alegre: Artmed, 2004.

RICHARDS, Mary Lynne. The clothing preferences and problems of elderly female consumers. The Gerontologist, v. 21, n. 3, p. 263267, jun. 1981.

SPIRDUSO, Waneen Wyrick. Dimensões físicas do envelhecimento. Barueri: Manole, 2005.

\section{Agradecimentos}

A Clínica Escola de Fisioterapia Sabrina Fiorentin Sfreddo da Universidade Comunitária da Região de Chapecó, e em especial as idosas do universo de pesquisa que foram elementos fundamentais na elaboração deste estudo. 